\title{
Pengukuran E-learning Readiness Pada Mahasiswa Sebagai Upaya Penerapan Pembelajaran Jarak Jauh Masa Pandemi COVID-19
}

\author{
Aprilia Sulistyohati \\ Program Studi Informatika, Universitas Indraprasta PGRI \\ email: aprilia6891@gmail.com
}

(Received: 28 Oktober 2020/ Accepted: 20 November 2020 / Published Online: 20 Desember 2020)

\begin{abstract}
Abstrak
Salah satu upaya untuk mengurangi kasus COVID-19 maka diberlakukan sistem Pembelajaran Jarak Jauh (PJJ) semua jenjang pendidikan. Penelitian ini bertujuan untuk mengetahui kesiapan mahasiswa Universitas Cikarang dalam penerapan e-learning. Pengukuran implementasi e-learning readiness dilakukan dengan menggunakan framework ELR. Dalam penelitian ini menggunakan framework ELR dengan 4 komponen utama yaitu teknologi, inovasi, manusia dan pengembangan diri. Penelitian ini dilakukan terhadap mahasiswa Fakultas Teknik Universitas Cikarang. Pengumpulan data menggunakan wawancara terstruktur dengan pihak manajemen kampus lalu dilanjutkan dengan penyebaran kuisioner, sedangkan pengolahan data menggunakan teknik statistik deskriptif kemudian dipetakan terhadap indeks e-learning Readiness. Hasil penelitian secara keseluruhan menunjukkan bahwa FT Universitas Cikarang berada pada level 3 (siap) dalam penerapan e-learning, namun masih memerlukan perbaikan dan persiapan di beberapa aspek untuk mencapai keberhasilan dalam implementasi e-learning. Beberapa rekomendasi diusulkan untuk Universitas Cikarang, yaitu tersedianya sistem e-learning yang dapat memenuhi kebutuhan mahasiswa untuk pembelajaran dan penugasan. Selain itu dari pihak kampus diharapkan dapat melakukan sosialisasi dan pelatihan mengenai e-learning kepada mahasiswa supaya mahasiswa lebih memahami sistem e-learning yang ada di Universitas Cikarang.
\end{abstract}

Kata kunci: Pengukuran E-learning Readiness, PJJ

\begin{abstract}
One of the efforts to reduce COVID-19 cases is a Distance Learning (PJJ) system for all levels of education. This study aims to determine the e-learning readiness of Cikarang University. Measurement of e-learning readiness implementation is carried out using the ELR framework. In this study, the ELR framework has consist of 4 main components, that are technology, innovation, people and self-development. This research was conducted on student in Cikarang University. Collecting data used structured interview with the campus management and then distributing questionnaires. The data processing used descriptive statistical techniques then mapped the e-learning Readiness index. The results of this study is to show that the Faculty of Engineering Cikarang University in the third level (ready) in implementing e-learning, but still requires improvement and preparation in several aspects to achieve success in implementing e-learning. Some recommendations are proposed for Cikarang University, that is the availability of an e-learning system that can fulfill students' need for learning and assigning. In addition, the campus is expected to be able to conduct socialization and training on e-learning to students so that it makes students understand the e-learning system at Cikarang University.
\end{abstract}

Keywords: Measurement of E-learning Readiness, PJJ

\section{PENDAHULUAN}

Penyebaran COVID-19 yang semakin meningkat di Indonesia sangat memberi dampak di berbagai aspek kehidupan salah satunya di bidang pendidikan. Segala upaya dilakukan pemerintah supaya jumlah kasus COVID-19 di Indonesia tidak meningkat, dimulai dari 
pembatasan sosial berskala besar (PSBB), pengaturan jarak fisik dan sosial (physical\&social distancing) di berbagai kalangan masyarakat. Melalui surat edaran Mendikbud RI no 3 Tahun 2020 tentang pencegahan COVID-19 pada satuan pendidikan mulai dari jenjang usia dini, dasar, menengah, dan tinggi mengambil langkah tegas sesuai himbauan pemerintah untuk melakukan aktivitas belajar di rumah (Kemendikbud RI, 2020). Pada jenjang pendidikan tinggi segala aktivitas yang biasanya dilakukan di kampus, saat pandemi ini dilakukan di rumah. Bukan hanya mahasiswa, para dosen dan tenaga pendidikan lainnya pun harus bekerja dari rumah. Dampak kebijakan pemerintah ini sangat dirasakan oleh semua perguruan tinggi, karena perguruan tinggi harus mengubah pelayanannya yang semula dilakukan secara konvensional menjadi pelayanan online (daring) (Susanti et al., 2020). Beberapa perguruan tinggi yang sudah menerapkan sistem blended learning tidak terlalu panik dengan kebijakan pemerintah tersebut. Hal ini dikarenakan teknologi dan sumber daya manusianya sudah dipersiapkan sebelumnya, walaupun belum $100 \%$ dijalankan secara online. Sistem blended learning merupakan proses pembelajaran yang memodifikasi pembelajaran tatap muka dan online antara dosen dan mahasiswa(Verawardina, 2020).

Dalam rangka memutus mata rantai penyebaran COVID-19 maka pemerintah mengeluarkan kebijakan social distancing. Social distancing merupakan pembatasan sosial/dalam berinteraksi dengan melakukan aktivitas sekolah, bekerja dan beribadah dari rumah. Social distancing diberlakukan untuk mengurangi interaksi sosial di luar rumah dan tidak menciptakan keramaian/kerumunan. Berdasarkan surat edaran no 4 tahun 2020 tentang pelaksanaan pendidikan dalam masa pandemi COVID-19 salah satunya yaitu proses belajar mengajar yang dilakukan dari rumah agar supaya kegiatan pembelajaran tetap dapat dilaksanakan secara maksimal. Sehingga diberlakukan sistem Pembelajaran Jarak Jauh (PJJ) untuk semua jenjang pendidikan. Sesuai dengan Permendikbud No.109/2013 (Pasal 2), PJJ bertujuan untuk memberikan layanan Pendidikan tinggi kepada kelompok masyarakat yang tidak dapat mengikuti Pendidikan secara tatap muka, dan untuk memperluas akses dan mempermudah layanan Pendidikan tinggi dalam pembelajaran (Kemendikbud RI, 2013). Konsep utama PJJ yaitu pemisahan fisik instruktur/dosen dan mahasiswa dengan menggunakan media teknologi (Darmawan, 2014; Kamarga, 2002). Teknologi yang digunakan dalam berinteraksi antara mahasiswa dan dosen dapat melalui e-learning, aplikasi zoom, google classroom, youtube, maupun media sosial whatsapp. Dalam PJJ berbasis $e$ learning ini selain dosen berperan sebagai pemberi materi namun juga berperan sebagai fasilitator agar tetap terjalin interaksi yang baik antara dosen dengan mahasiswa dan antara mahasiswa satu dengan yang lain walaupun tidak bertatap muka secara langsung.

E-learning atau pembelajaran online yaitu pembelajaran yang pelaksanaannnya didukung oleh jasa/media elektronik (audio, telepon, transmisi satelit atau komputer) (Darmawan, 2014). E-learning merupakan kegiatan pembelajaran yang memanfaatkan jaringan (internet, LAN, WAN) sebagai metode penyampaian, interaksi, dan fasilitas lain yang mendukung layanan belajar (Khatimi, 2006; Putra, 2018). E-learning merupakan salah satu pemikiran dalam upaya mengintegrasikan proses pembelajaran dari pembelajaran tradisional, pembelajaran jarak jauh dan blended learning (Darmawan, 2014).

Salah satu tantangan dalam penerapan e-learning yaitu kesiapan lembaga pendidikan dalam menggunakan media pembelajaran e-learning (Agustina, 2016), selain itu dari sisi organisasi perlu adanya kebijakan, komitmen pimpinan, serta penyediaan fasilitas e-learning yang sangat dibutuhkan dalam menggiring dan mensosialisasikan proses perubahan ini. Beberapa faktor keberhasilan penerapan e-learning yaitu adanya sikap positif dari mahasiswa dan tenaga pendidik terhadap teknologi komputer dan internet, dukungan dari organisasi dalam menyediakan fasilitas pembelajaran melalui pemanfaatan teknologi dan jaringan.

Sukses atau tidaknya penerapan e-learning dalam jenjang pendidikan tinggi perlu adanya pemeriksaan/pengukuran untuk menentukan faktor-faktor kesiapan yang perlu 
diperbaiki ataupun ditambahkan agar penerapan e-learning berjalan maksimal seperti yang diharapkan. Penelitian sejenis pernah dilakukan dengan mempertimbangkan komponen human resources, kultur organisasi, teknologi, kebijakan, keuangan organisasi dan infrastruktur (Fariani, 2013). Namun komponen inovasi dan pengembangan diri belum dimasukkan ke dalam penelitian tersebut. Sehingga penulis menggunakan komponen yang belum digunakan pada penelitian sebelumnya untuk mengukur e-learning readiness. Elearning disuatu lingkungan organisasi harus memiliki kesiapan dalam aspek teknologi (Surjono, 2010), selain itu supaya penerapan e-learning dalam proses pembelajaran di sekolah dapat berjalan dengan sukses, maka perlu melakukan evaluasi untuk mengetahui tingkat kesiapan sekolah tersebut untuk penerapan e-learning dalam proses pembelajaran di sekolah (Waryanto \& Insani, 2013). Penilaian kesiapan e-learning perlu diketahui untuk menganalisa faktor-faktor apa yang perlu ditingkatkan agar dapat menunjang kegiatan pembelajaran dan mampu meningkatkan prestasi hasil belajar mahasiswa. E-readiness memiliki andil dalam kesuksesan program pendidikan yang menggunakan teknologi informasi dan komunikasi untuk kegiatan akademik (Kaur, 2004). Rosenberg juga berpendapat bahwa e-learning readiness merupakan instrumen yang efektif untuk mengevaluasi efektifitas strategi organisasi dan efektifitas program e-learning dalam menerapkan e-learning (Priyanto, 2017). Model ELR (e-learning readiness) dikembangkan untuk melakukan evaluasi e-learning di negara berkembang (Fajri, 2018; Fariani, 2013).

Model ELR merupakan sebuah framework yang terdiri dari empat faktor yang mampu mengukur kesiapan e-learning yaitu teknologi, inovasi, manusia, pengembangan diri (Fajri, 2018; Faslah \& Santoso, 2017). Model ELR meliputi beberapa faktor yaitu faktor teknologi, merupakan sarana yang digunakan untuk melakukan perbaikan kegiatan pembelajaran dengan mempertimbangkan cara untuk mengefektifkan adaptasi dari inovasi teknologi yaitu e-learning dalam suatu organisasi. Faktor inovasi, merupakan pembaharuan atau perubahan yang ditandai oleh adanya hal yang baru. Faktor inovasi mempertimbangkan pengalaman dari sumber daya manusia di organisasi dalam mengadopsi e-learning. Faktor manusia, merupakan kemampuan sumber daya manusia pada sebuah organisasi dalam mengadopsi inovasi baru yaitu e-learning. Faktor pengembangan diri, merupakan kesiapan organisasi dalam menerapkan e-learning dan kesiapan mahasiswa terhadap pengembangan dirinya sendiri untuk mengadopsi e-learning.

Universitas Cikarang merupakan salah satu universitas terkemuka di Kab. Bekasi yang sudah menerapkan blended learning. Sebelum adanya pandemi COVID-19 sistem e-learning sudah diterapkan pada universitas tersebut untuk penilaian mahasiswa, sedangkan untuk perkuliahan tetap dilakukan secara tatap muka offline. Semenjak adanya pandemi COVID-19 penerapan sistem e-learning semakin ditingkatkan supaya perkuliahan online berjalan secara maksimal (Susanti \& Putri, 2020). Namun penerapan sistem $e$ - learning tersebut belum pernah dilakukan pengukuran, sehingga perlu dilakukan pengukuran sejauh mana kesiapan mahasiswa (self assessment) untuk mengikuti proses pembelajaran secara e-learning. Tujuan dari penelitian ini yaitu untuk menganalisis dan mengukur tingkat kesiapan penerapan $e$ learning di Fakultas Teknik Universitas Cikarang.

\section{METODE}

Penelitian ini dilakukan di Fakultas Teknik Universitas Cikarang pada bulan April 2020. Penelitian ini juga merupakan jenis penelitian explanatif, yaitu dengan menjelaskan dan mendalami variabel penelitian berdasarkan data yang diperoleh dari survey, wawancara, dan observasi. Penelitian ini menggunakan analisis data kuantitatif deskriptif. Adapun tahapan penelitian yang dilakukan, yaitu tahap pertama studi literatur dan rumusan masalah dengan menggunakan data primer kualitatif dan kuantitatif serta data sekunder. Data primer kualitatif didapat dari hasil wawancara terhadap pihak manajemen Universitas Cikarang 
terkait kondisi organisasi. Data primer kuantitatif didapat melalui survey menggunakan kuisioner sebagai alat pengumpulan data. Data sekunder berupa studi literatur dari penelitian sebelumnya dengan topik sejenis.

Tahap kedua penentuan variabel penelitian, yang meliputi variabel teknologi, inovasi, manusia dan pengembangan diri. Dari masing-masing variabel terdiri dari beberapa indikator. Indikator-indikator tersebut sudah disesuaikan kondisi objek penelitian. Variabel teknologi terdiri dari 9 indikator, variabel inovasi terdiri dari 3 indikator, variabel manusia terdiri 2 indikator, variabel pengembangan diri terdiri dari 3 indikator. Sehingga jumlah keseluruhan 17 indikator.

Tahap ketiga perancangan kuesioner, instrumen kuesioner merupakan hasil adopsi dari penelitian sejenis sebelumnya dan disesuaikan dengan karateristik Universitas Cikarang. Penentuan jawaban responden diukur menggunakan skala likert dengan 5 skala. Terdapat 5 pilihan jawaban dengan bobot nilai yang telah ditentukan. Pembobotan nilai dapat dilihat pada tabel 1.

Tabel 1. Pembobotan Nilai Skala Likert

\begin{tabular}{cc}
\hline Jawaban & Bobot Nilai \\
\hline Sangat Tidak Setuju (STS) & 1 \\
Tidak Setuju (TS) & 2 \\
Netral (N) & 3 \\
Setuju (S) & 4 \\
Sangat Setuju (SS) & 5 \\
\hline
\end{tabular}

Tahap keempat pengumpulan data melalui wawancara dengan pihak manajemen Universitas dan menyebar kuesioner secara online melalui link kuesioner melalui google form yang dikirimkan pada 6 grup whatsapp. Pengumpulan data dilakukan pada tanggal 6 April 2020 - 27 April 2020. Populasi yang digunakan yaitu mahasiswa Fakultas Teknik Universitas Cikarang (teknik informatika, teknik industri, teknik sipil, teknik lingkungan, arsitek). Kemudian pengambilan sampel dilakukan secara simple random sampling dengan kriteria responden sebagai pengguna sistem e-learning di lingkungan Fakultas Teknik Universitas Cikarang. Penentuan jumlah sample minimal berdasarkan teori Slovin dengan batas toleransi kesalahan $10 \%$ berarti memiliki tingkat akurasi $90 \%$, maka jumlah sample yang dihasilkan adalah 88 responden. Menurut teori Central Limit Theorm (CLT) jumlah responden minimal 30 responden (Juwono, 2016). Jumlah sample pada penelitian ini adalah 120 responden. Jumlah tersebut sudah memenuhi teori Slovin dan CLT.

Tahap kelima pengolahan dan analisis data, pengolahan data dimulai dengan mengelompokkan data hasil kuesioner berdasarkan variabel penelitian, kemudian dilakukan uji coba instrumen melalui uji validitas yang digunakan untuk menguji kesesuaian dari kuesioner dalam mengukur variabel penelitian. Kemudian dilanjutkan uji reliabilitas untuk membuktikan akurasi, konsistensi, dan ketepatan instrumen dalam mengukur variabel. Perhitungan uji validitas dan reliabilitas menggunakan software SPSS. Statistik deskriptif digunakan untuk mencari nilai rata-rata dari seluruh jawaban kuisioner untuk setiap kelompok variabel penelitian. Dalam melakukan pengkategorian tingkat kesiapan menggunakan model indeks dari Aydin dan Tascii (Aydin, 2005). Tingkat kesiapan $e$ learning dapat dilihat pada Tabel 2. Tahapan selanjutnya yaitu menentukan indeks e-learning readiness untuk setiap indikator, kemudian menentukan indeks e-learning readiness dan melakukan analisis dari masing-masing variabel penelitian. 
Tabel 2. Kategori Tingkat Kesiapan e-learning (Aydin, 2005)

\begin{tabular}{|c|c|c|}
\hline Level & Kategori & Keterangan \\
\hline 1 & $<2.59$ & $\begin{array}{c}\text { Tidak siap dan butuh banyak persiapan untuk mencapai } \\
\text { keberhasilan }\end{array}$ \\
\hline 2 & $2,6-3,39$ & $\begin{array}{c}\text { Belum siap dan memerlukan beberapa persiapan untuk } \\
\text { mencapai keberhasilan }\end{array}$ \\
\hline 3 & $3,4-4,19$ & $\begin{array}{c}\text { Siap namun masih memerlukan sedikit perbaikan di } \\
\text { beberapa aspek }\end{array}$ \\
\hline 4 & $4,2-5$ & Sangat siap untuk implementasi \\
\hline
\end{tabular}

\section{HASIL DAN PEMBAHASAN}

Hasil

Pada penelitian ini, pengujian instrumen melalui uji validitas dengan menggunakan tingkat signifikansi 5\%, adapun nilai $\mathrm{r}_{\text {tabel }}$ untuk signifikansi $5 \%$ yaitu 0.178 . Kriteria uji validitas jika $r_{\text {hitung }}>r_{\text {tabel }}$, maka butir soal tersebut valid, namun jika $r_{\text {hitung }}<r_{\text {tabel }}$ maka butir soal tersebut dapat dinyatakan tidak valid. Dari hasil pengujian masing-masing butir soal dinyatakan valid karena nilai $r_{\text {hitung }}>r_{\text {tabel. }}$ Kriteria uji reliabilitas jika nilai cronbach's alpha $>$ $\mathrm{r}_{\text {tabel}}$, maka instrumen tersebut dinyatakan reliable/konsisten. Hasil pengujian reliabilitas dengan menggunakan SPSS yaitu nilai cronbach's alpha $=0.667(>.0 .178)$, sehingga instrumen tersebut dinyatakan reliable/konsisten karena nilai alpha $>r_{\text {tabel. }}$

Penelitian ini menggunakan 4 variabel dengan 17 indikator. Variabel teknologi, terdiri dari 9 indikator yang dapat dilihat pada tabel 3. Gambaran e-learning readiness untuk masing-masing indikator pada variabel teknologi dapat dilihat pada gambar 1. Dari gambar 1 dapat dilihat bahwa skala tertinggi pada indikator T4 yaitu mahasiswa memiliki kemampuan komputer dasar (misalnya: mengetik, mengakses internet, menyunting file, dll) nilainya sebesar 3,83. Skala terendah pada indikator T9 yaitu mahasiswa menerima sistem pembelajaran yang membutuhkan penggunaan teknologi e-learning untuk menyelesaikan tugas harian sebesar 3,23.

Tabel 3. Indikator pada variabel teknologi

\begin{tabular}{cc}
\hline $\begin{array}{c}\text { Kode } \\
\text { indikator }\end{array}$ & Nama indikator \\
\hline T1 & Kampus menyediakan akses internet di lingkungan kampus \\
T2 & Mahasiswa dapat mengakses Internet dari luar kampus \\
T3 & Kecepatan akses internet di kampus cukup untuk mendukung $e$ - \\
& learning \\
T4 & Mahasiswa memiliki kemampuan komputer dasar \\
T5 & Mahasiswa memiliki kemampuan internet dasar \\
T6 & Mahasiswa memiliki kemampuan untuk mengikuti petunjuk/arahan \\
& pada layar komputer untuk menyelesaikan tugas pada $e$-learning \\
T7 & Mahasiswa bersedia / antusias dalam menggunakan $e$-learning untuk \\
& menyelesaikan tugas-tugasnya \\
T8 & Mahasiswa lebih memilih menggunakan dokumen digital / softcopy \\
& daripada hardcopy \\
T9 & Mahasiswa menerima sistem pembelajaran yang membutuhkan \\
& penggunaan teknologi $e$-learning untuk menyelesaikan tugas harian \\
\hline
\end{tabular}




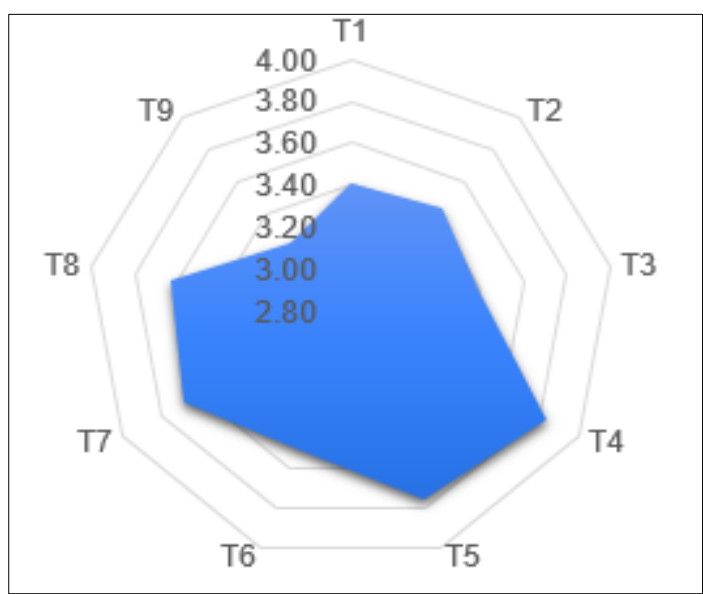

Gambar 1. Skala indikator variabel teknologi

Variabel inovasi, terdiri dari 3 indikator yang dapat dilihat pada tabel 4. Gambaran $e$ learning readiness untuk masing-masing indikator pada variabel inovasi dapat dilihat pada gambar 2. Dari gambar 2 dapat dilihat bahwa skala tertinggi pada indikator I3 yaitu mahasiswa menerima perubahan proses pembelajaran dengan menggunakan e-learning nilainya sebesar 3,49. Skala terendah pada indikator I2 yaitu mahasiswa selalu menerima setiap pembaharuan teknologi yang diterapkan oleh pihak kampus sebesar 3,26.

Tabel 4. Indikator pada variabel inovasi

\begin{tabular}{cl}
\hline $\begin{array}{c}\text { Kode } \\
\text { indikator }\end{array}$ & \multicolumn{1}{c}{ Nama indikator } \\
\hline I1 & $\begin{array}{l}\text { Mahasiswa dapat mengadaptasi perubahan / inovasi e-learning } \\
\text { dengan mudah }\end{array}$ \\
I2 & $\begin{array}{l}\text { Mahasiswa selalu menerima setiap pembaharuan teknologi yang } \\
\text { diterapkan oleh pihak kampus }\end{array}$ \\
I3 & $\begin{array}{l}\text { Mahasiswa menerima perubahan proses pembelajaran dengan } \\
\text { menggunakan e-learning }\end{array}$ \\
\hline
\end{tabular}

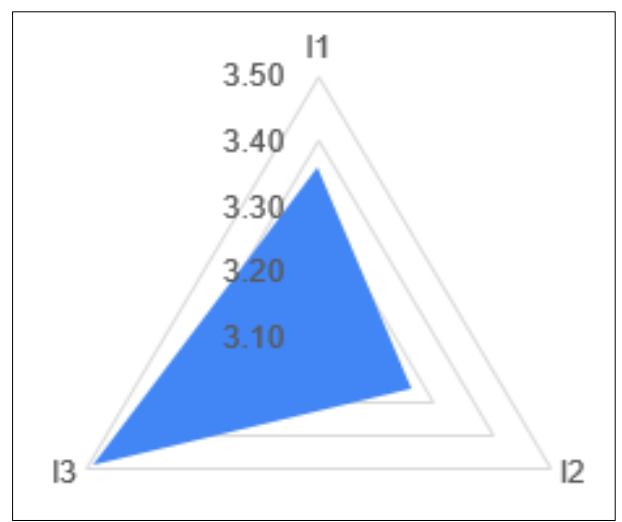

Gambar 2. Skala indikator variabel inovasi

Variabel manusia, terdiri dari 2 indikator yang dapat dilihat pada tabel 5. Gambaran $e$ learning readiness untuk masing-masing indikator pada variabel manusia dapat dilihat pada gambar 3. Dari gambar 3 dapat dilihat bahwa skala tertinggi pada indikator M2 yaitu mahasiswa dapat menggunakan e-learning nilainya sebesar 3,52. Skala terendah pada indikator M1 yaitu mahasiswa sudah memahami apa itu e-learning sebesar 3,46. 
Tabel 5. Indikator pada Variabel Teknologi

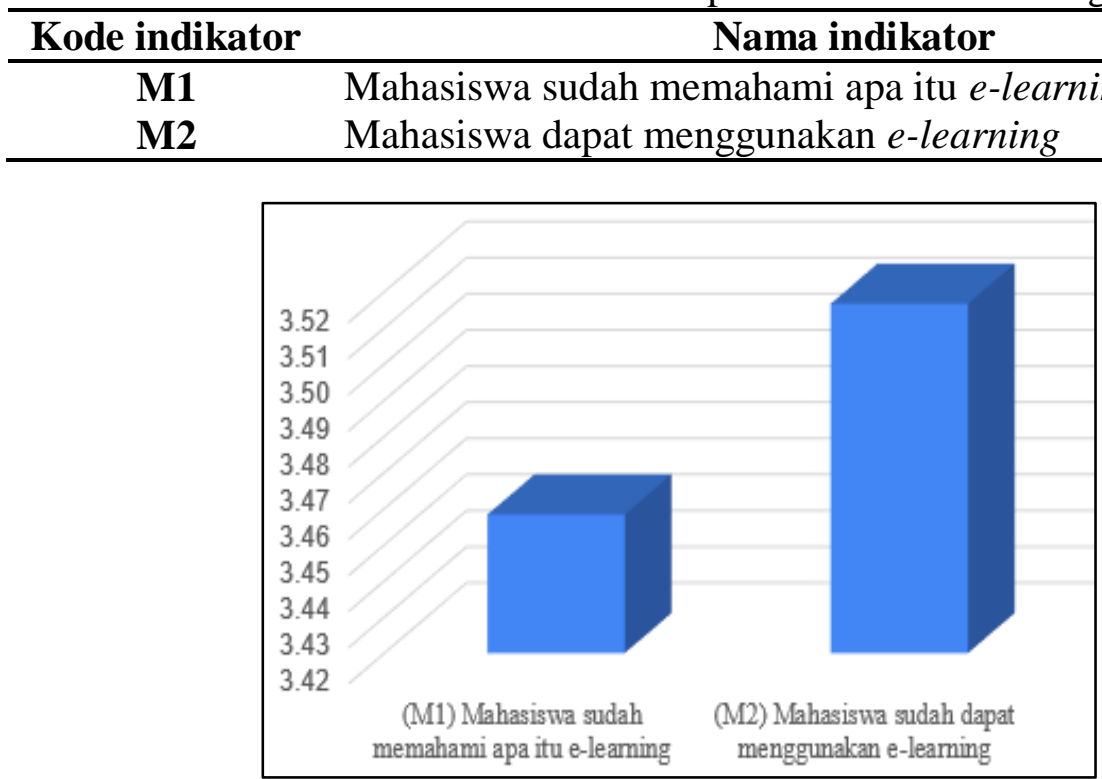

Gambar 3. Skala Indikator Variabel Manusia

Variabel pengembangan diri, terdiri dari 3 indikator yang dapat dilihat pada tabel 6 . Gambaran e-learning readiness untuk masing-masing indikator pada variabel pengembangan diri dapat dilihat pada gambar 4. Dari gambar 4 dapat dilihat bahwa skala tertinggi pada indikator P3 yaitu Mahasiswa dengan senang hati dan antusias dalam mengikuti proses pembelajaran melalui e-learning nilainya sebesar 3,64. Skala terendah pada indikator P1 yaitu kampus mengadakan pelatihan e-learning untuk mahasiswa nilainya sebesar 3,03.

Tabel 6. Indikator pada Variabel Teknologi

\begin{tabular}{cl}
\hline $\begin{array}{c}\text { Kode } \\
\text { indikator }\end{array}$ & \multicolumn{2}{c}{ Nama indikator } \\
\hline P1 & Kampus mengadakan pelatihan e-learning untuk mahasiswa \\
P2 & $\begin{array}{l}\text { Mahasiswa meluangkan waktu secara khusus untuk belajar } \\
\text { menerapkan e-learning }\end{array}$ \\
P3 & $\begin{array}{l}\text { Mahasiswa dengan senang hati dan antusias dalam mengikuti } \\
\text { proses pembelajaran melalui e-learning }\end{array}$ \\
\hline
\end{tabular}

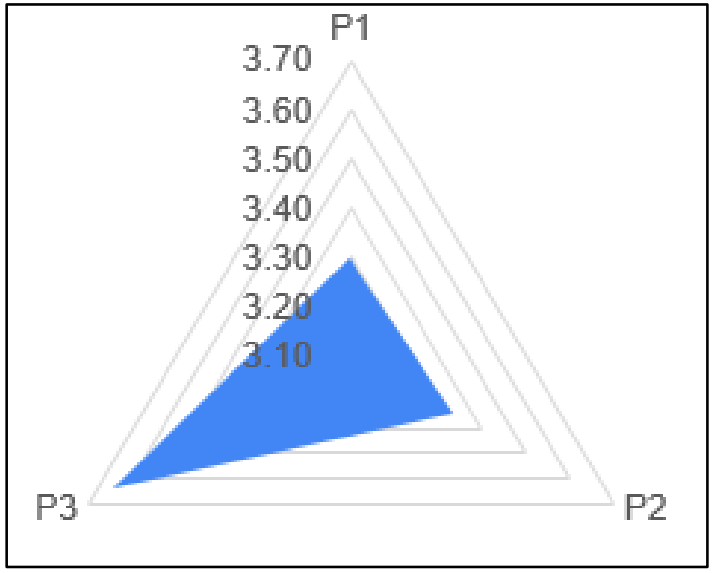

Gambar 4. Skala indikator variabel pengembangan diri 


\section{Pembahasan}

Berdasarkan hasil pengukuran e-learning readiness didapat bahwa Universitas Cikarang memiliki indeks $e$-learning readiness berada pada level 3 (range 3,4-4,19) dengan nilai 3,46. Jika dilihat dari setiap variabel penelitian, maka didapat variabel teknologi memiliki skala 3,54, variabel manusia memiliki skala 3,49, variabel inovasi memiliki skala 3,37 , dan variabel pengembangan diri memiliki skala 3,43. Hal tersebut menunjukkan bahwa secara keseluruhan implementasi e-learning di Fakultas Teknik Universitas Cikarang menunjukkan level "Siap" namun masih memerlukan perbaikan di beberapa aspek. Rangkuman hasil pengukuran e-learning readiness dapat dilihat pada gambar 5 .

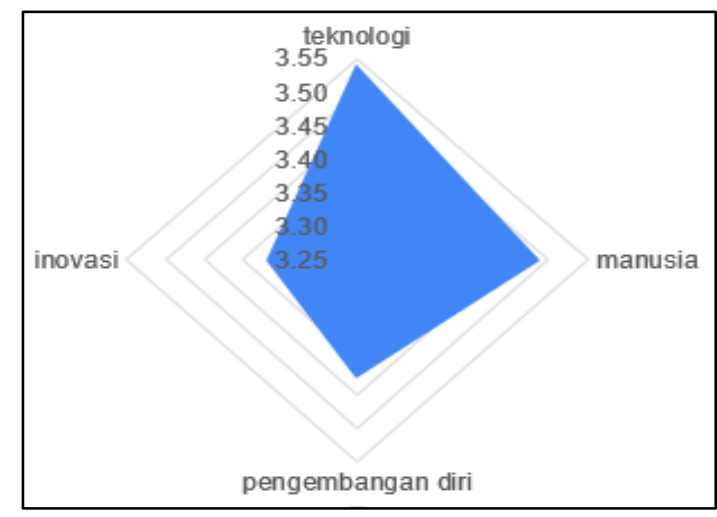

Gambar 5. Radar Chart dari Keseluruhan Variabel e-learning readiness

Selanjutnya tampak bahwa secara keseluruhan skala kesiapan e-learning. Pada Gambar 5 menunjukkan bahwa aspek dengan nilai terkecil berada pada variabel inovasi yang merupakan pembaharuan atau perubahan yang ditandai oleh adanya hal yang baru. Inovasi disini dapat berupa praktek-praktek tertentu untuk memecahkan suatu permasalahan dan memperbaiki suatu keadaan tertentu. Pada variabel inovasi, indikator mahasiswa selalu menerima setiap pembaharuan teknologi yang diterapkan oleh pihak kampus (I2) bernilai 3,26. Hal ini berarti mahasiswa Fakultas Teknik Universitas Cikarang hanya menerima hasil akhir pembaharuan teknologinya saja tanpa adanya komunikasi antara sistem yang dibutuhkan mahasiswa dengan pihak kampus terkait pembaharuan teknologi tersebut. Hal ini berbanding lurus dengan variabel pengembangan diri khususnya indikator P1 yaitu kampus mengadakan pelatihan e-learning untuk mahasiswa. Indikator P1 juga memiliki skala kecil yaitu 3,30 dikarenakan pihak kampus tidak mengadakan pelatihan e-learning untuk mahasiswa, sehingga mahasiswa memahami sistem e-learning secara otodidak dan hasilnya kurang maksimal.

Dari hasil analisa dan pembahasan di atas, komponen inovasi dan pengembangan diri pada penelitian ini dapat melengkapi dari komponen penelitian sebelumnya (Fariani, 2013) yaitu human resources, kultur organisasi, teknologi, kebijakan, keuangan organisasi dan infrastruktur. Keterkaitan penelitian terhadap bidang e-learning readiness berkaitan dengan penentuan komponen e-learning readiness yang dapat dijadikan sebagai elemen penelitian. Rekomendasi yang diajukan sebagai hasil penelitian didasarkan pada komponen-komponen tersebut. Penulis berharap komponen e-learning readiness dapat digunakan untuk penelitian yang akan datang khususnya perguruan tinggi. Namun perlu ditinjau kembali kesesuaian komponen e-learning readiness yang disesuaikan dengan karakteristik masing-masing organisasi. 


\section{SIMPULAN}

Hasil studi literatur dan pengamatan didapat komponen e-learning Readiness meliputi teknologi, inovasi, manusia dan pengembangan diri. Dengan menggunakan framework ELR telah dilakukan penelitian terhadap Universitas Cikarang dimana didapat indeks e-learning Readiness sebesar 3,46, yang berarti secara keseluruhan implementasi e-learning di Fakultas Teknik Universitas Cikarang menunjukkan level "Siap" namun masih memerlukan perbaikan di beberapa aspek. Fakultas Teknik Universitas Cikarang masih memerlukan perbaikan dan persiapan untuk mencapai keberhasilan dalam implementasi e-learning di lingkungan kampus khususnya Fakultas Teknik. Beberapa rekomendasi diusulkan untuk Universitas Cikarang terkait dengan penelitian ini, yaitu tersedianya sistem e-learning yang dapat memenuhi kebutuhan mahasiswa untuk proses pembelajaran dan penugasan. Selain itu dari pihak kampus diharapkan dapat melakukan sosialisasi dan pelatihan mengenai e-learning kepada mahasiswa supaya mahasiswa lebih mengenal dan memahami sistem $e$-learning yang ada di Universitas Cikarang.

\section{REFERENSI}

Agustina, R. (2016). Sejarah, tantangan, dan faktor keberhasilan dalam pengembangan elearning. Seminar Nasional Sistem Informasi Indonesia, 210-218. Surabaya: SESINDO,

Aydin, T. (2005). Measuring Readiness for e-Learning: Reflections from an Emerging Country. International Forum of Educational Technology \& Society Journal of Educational, 7(4), 244-257.

Darmawan, D. (2014). Pengembangan E-learning Teori dan Desain (1st ed.). Bandung: PT Remaja Rosdakarya.

Fajri, S. (2018). Pengukuran Tingkat Kesiapan Penerapan E-Learning Di SMK $N 1$ Banyumas. Universitas Negeri Yogyakarta.

Fariani, R. I. (2013). Pengukuran Tingkat Kesiapan E-Learning (E-Learning Readiness). Seminar Nasional Aplikasi Teknologi Informasi (SNATI), G1-G7. Yogyakarta: Unviersitas Islam Indoensia.

Faslah, R., \& Santoso, H. B. (2017). Analisis Kesiapan Implementasi E-Learning Menggunakan E-Learning Readiness Model. POSITIF: Jurnal Sistem dan Teknologi Informasi, 3(2), 113-120. https://doi.org/10.31961/positif.v3i2.431

Juwono, T. (2016). Metode Sampling dan Teorema Central Limit Mengapa Perlu Sampling (Issue March). Surya University, Tangerang.

Kamarga, H. (2002). Belajar sejarah melalui e-learning. Jakarta: PT. Inti Media.

Kaur, K. (2004). An Assessment of e-Learning Readiness at the Open University Malaysia. International Conference on Computers in Education (ICCE2004), 1-8. Malaysia: Open University Malaysia. http://library.oum.edu.my/repository/id/eprint/115

Kemendikbud RI. (2013). Permenkes RI Nomor 109 Tahun 2013. 1-8.

Kemendikbud RI. (2020). Surat Edaran No 3 tentang Pencegahan COVID-19 pada Satuan Pendidikan.

Khatimi, H. (2006). Mengenal E-learning Sebagai Salah satu Bentuk Kegiatan Pembelajaran. 7(2), 72-81.

Priyanto. (2017). Model E-Learning Readiness Sebagai Strategi Pengembangan E-Learning. International Seminar Proceedings, Information And Communication Technology (ICT) In Education, 267-275. Yogyakarta: Universitas Negeri Yogyakarta

Putra, Y. (2018). Sistem Informasi Manajemen: Pengenalan Model Pembelajaran eLearning. Universitas Mercu Buana, Jakarta. http://43217110334.blog.mercubuana.ac.id/2018/12/25/pengenalan-e-learning/

Surjono, H. D. (2010). Membangun Course E - Learning Berbasis Moodle. Yogyakarta:UNY Press. 
Susanti, W., \& Putri, R. N. (2020). Penerapan Cloud Computing Sebagai Media Pembelajaran Berbasis Online Masa Pandemi Covid-19. JOISIE (Journal Of Information System And Information Engineering, 4(1), 56-61.

Susanti, W., Yuliendi, R. R., Ambiyar, A., \& Wakhinuddin, W. (2020). Perancangan Pembelajaran E-Learning Bahasa Inggris untuk Pemula Berbasis Multimedia. Edukasi: Jurnal Pendidikan, 18(1), 101-112. https://doi.org/10.31571/edukasi.v18i1.1601

Verawardina, U. (2020). Reviewing online learning facing the Covid-19 outbreak. Talent Development and Excellence Journal, 12(3), 385-392.

Waryanto, N. H., \& Insani, N. (2013). Tingkat Kesiapan (Readiness) Implementasi ELearning di Sekolah Menengah Atas Kota Yogyakarta. Jurnal Pendidikan Matematika dan Sains, 1(2), 117-124. 